\title{
DESIGN AND ANALYSIS OF THE CRYOPUMP FOR THE DIII-D UPPER DIVERTOR
}

\author{
by \\ E.E. REIS, C.B. BAXI, and A.S. BOZEK
}

This is a preprint of a paper to be presented at the 18th IEEE/NPSS Symposium on Fusion Engineering, October 25-29, 1999, in Albuquerque, New Mexico, and to be published in the Proceedings.

\author{
Work supported by \\ the U.S. Department of Energy \\ under Contract No. DE-AC03-99ER54463
}




\section{DISCLAIMER}

This report was prepared as an account of work sponsored by an agency of the United States Government. Neither the United States Government nor any agency thereof, nor any of their employees, make any warranty, express or implied, or assumes any legal liability or responsibility for the accuracy, completeness, or usefulness of any information, apparatus, product, or process disclosed, or represents that its use would not infringe privately owned rights. Reference herein to any specific commercial product, process, or service by trade name, trademark, manufacturer, or otherwise does not necessarily constitute or imply its endorsement, recommendation, or favoring by the United States Government or any agency thereof. The views and opinions of authors expressed herein do not necessarily state or reflect those of the United States Government or any agency thereof. 


\section{DISCLAIMER}

Portions of this document may be illegible in electronic image products. Images are produced from the best available original document. 


\title{
Design and Analysis of the Cryopump for the DIII-D Upper Divertor*
}

\author{
E.E. Reis, C.B. Baxi, and A.S. Bozek \\ General Atomics, P.O. Box 85608, San Diego, California 92186-5608
}

\begin{abstract}
A cryocondensation pump for the upper inboard divertor on DIII-D is to be installed in the vacuum vessel in the fall of 1999. The cryopump removes neutral gas particles from the divertor and prevents recycling to the plasma. This pump is designed for a pumping speed of $18,000 \mathrm{\ell} / \mathrm{s}$ at $0.4 \mathrm{mTorr}$. The cryopump is toroidally continuous to minimize inductive voltages and avoid electrical breakdown during disruptions. The cryopump consists of a $25 \mathrm{~mm}$ Inconel tube cooled by liquid helium and is surrounded by nitrogen cooled shields. A segmented ambient temperature radiation/particle shield protects the nitrogen shields.
\end{abstract}

The pump is subjected to a steady state heat load of less than $10 \mathrm{~W}$ due to conduction and radiation heat transfer. The helium tube will be subjected to Joule heating of less than $300 \mathrm{~J}$ due to induced current and a particle load of less than $12 \mathrm{~W}$ during plasma operation. The thermal design of the cryopump requires that it be cooled by $5 \mathrm{~g} / \mathrm{s}$ liquid helium at an inlet pressure of $115 \mathrm{kPa}$ and a temperature of $4.35 \mathrm{~K}$. Thermal analysis and tests show that the helium tube can absorb a transient heat load of up to $100 \mathrm{~W}$ for $10 \mathrm{~s}$ and still pump deuterium at $6.3 \mathrm{~K}$.

Disruptions induce toroidal currents in the helium line and nitrogen shields. These currents cross the rapidly changing magnetic fields, applying complex dynamic loads on the cryopump. The forces on the pump are extrapolated from magnetic measurements from DIII-D plasma disruptions and scaled to a 3 MA disruption. The supports for the nitrogen shield consist of a racetrack design, which are stiff for reacting the disruption loads, but are radially flexible to allow differential thermal displacements with the vacuum vessel. Static and dynamic finite element analyses of the cryopump show that the stresses and displacements over a range of disruption and thermal loadings are acceptable.

\section{INTRODUCTION}

Divertor experiments at DIII-D were initiated in 1989 with the Advanced Divertor Program (ADP). This program was very successful in controlling the recycling of impurities to the plasma by pumping and biasing of a ring electrode in the lower region of the vacuum vessel [1,2]. The knowledge gained in the ADP led to the development of the Radiative Divertor Program (RDP). The first phase of the RDP is the installation of pumping plenums and cryopumps in the upper section of the vacuum vessel. The installation of the upper outer baffle and cryopump was completed in 1996 [3,4]. The private flux baffle and upper inboard cryopump is scheduled to be installed in the fall of 1999.

The purpose of the RDP is to provide density control in high triangularity single or double null plasma discharges. The
RDP will also allow the study of dissipating divertor power by radiation achieved by puffing gas in the divertor region, thereby distributing the power over a larger area. However, gas puffed in the divertor sometimes ends up in the plasma core, degrading the quality of confinement. The design of the cryopumps and baffle structures limit this core fueling by entrainment of neutral gas particles under the divertor.

A cross section of the completed upper divertor is shown in Fig. 1. The divertor hardware consists of private flux and outer baffle plates and two cryopumps. The cryopump consists of a toroidally continuous tube with liquid helium flowing inside and is surrounded by liquid nitrogen cooled shields and radiation shields. The cryopump supports to the vacuum vessel utilize a race track design which provides radial flexibility for differential displacements and vertical stiffness for reacting disruption loading. Low heat leak supports were designed for supporting the cryopump helium line and its long feedline. The design and installation of the liquid helium and nitrogen transfer lines to the cryopumps is presented in Ref. [5].

\section{MECHANICAL AND THERMAL DESIGN}

The inboard cryopump designed for the DIII-D upper divertor is similar to the outer cryopump for the lower

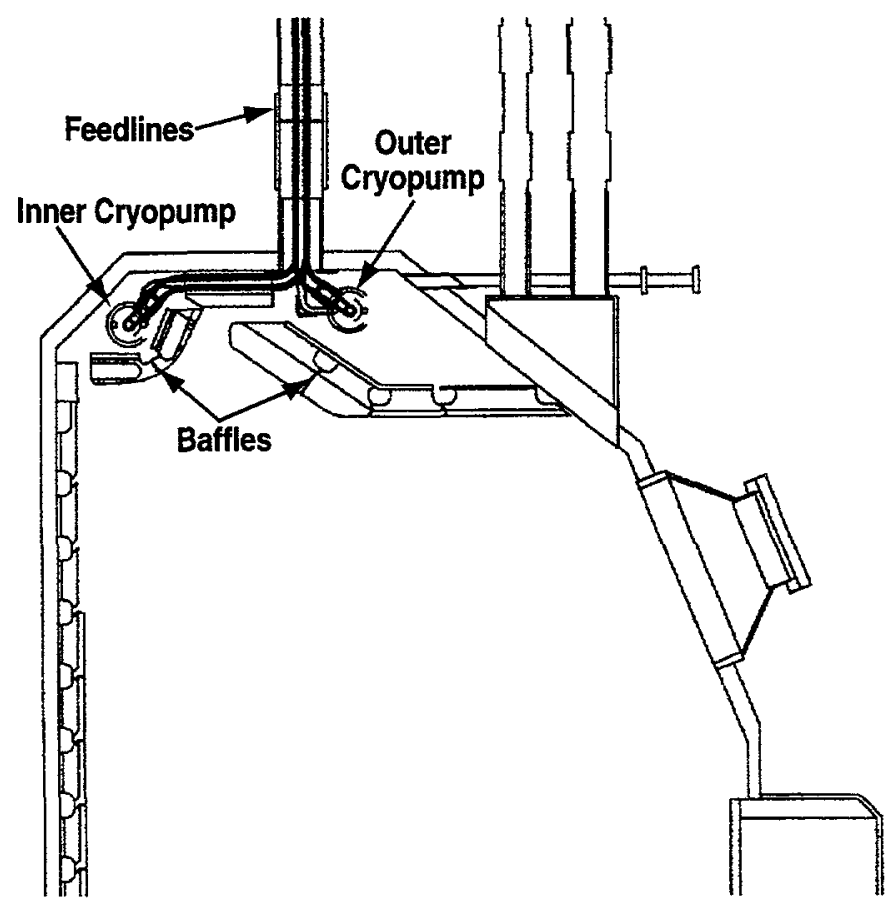

Fig. 1. Cross-section of completed upper divertor.

*Work supported by U.S. Department of Energy under Contract No. DE-AC03-99ER54463. 
divertor. The primary differences in the two designs are the number of supports to the vacuum vessel (12 versus 24$)$ and the stiffness of the supports are much higher for the upper cryopump. Also, the lengths of the helium and nitrogen feedlines between the cryopump and the end of the vessel port were increased, necessitating the need for intermediate supports for the feedlines.

All cryopumps in DIII-D are designed to allow toroidal currents to flow during current ramp-up and disruptions. This design concept was selected because of concern over certain possible voltage breakdowns between the vessel wall and the pump due to ionized gas in the pumping plenum. The toroidally continuous cryopump has the advantage of lowering the voltage potential between the vessel wall and the pump to less than $50 \mathrm{~V}$. Since the cryopump must be engineered to withstand the disruption loads, it was decided to design a toroidally continuous pump that can routinely react these currents.

The cross-sections of the upper cryopumps are shown in Fig. 1. The inner pump is about $7 \mathrm{~m}$ in circumference and the outer pump has a circumference of $10 \mathrm{~m}$. The pumping surface is a $25 \mathrm{~mm}$ diameter coaxial tube with helium flow through the annulus. Surrounding the pump surfaces are liquid nitrogen cooled shields which provide protection from energetic particles and limit the steady state heat load on the helium tubes. A warm radiation/particle shield to prevent energetic particles from releasing condensed water surrounds the nitrogen shield. The nitrogen shields are coated with an emissivity enhancing coating to absorb most of the incoming photon energy. The shields are plasma sprayed with copper strips to maintain a maximum temperature below $110 \mathrm{~K}$.

The upper cryopumps are supported from the vessel by an evenly spaced series of hoop spring brackets as shown in Fig. 2. Twelve support brackets are required for the inner cryopump and 24 are used for the outer pump. The support brackets are designed to allow for the thermal contraction of the pumps at cryogenic temperatures with the vessel at $25^{\circ} \mathrm{C}$. The supports were designed to be stiff in the vertical direction to minimize the displacements caused by disruption loads. The hoop brackets are fabricated from Inconel 718 to react the disruption loads without yielding.

The helium tubes are supported from the inner nitrogen shield by the conically wound spring standoffs shown in Fig. 3. These supports provide a long heat path and ceramic rings provide electrical isolation from the nitrogen shells. The conductive heat load to the helium tube for the 24 support design is less than $1 \mathrm{~W}$.

The vertical run of the helium feedlines requires special standoffs to prevent contact with its nitrogen shield during operational loading conditions. The standoffs are also required for increasing the fundamental frequency of the helium feedline so that it is not in resonance with the vertical motion of the vacuum vessel due to plasma disruptions. The low heat leak support shown in Fig. 4 is required at three locations

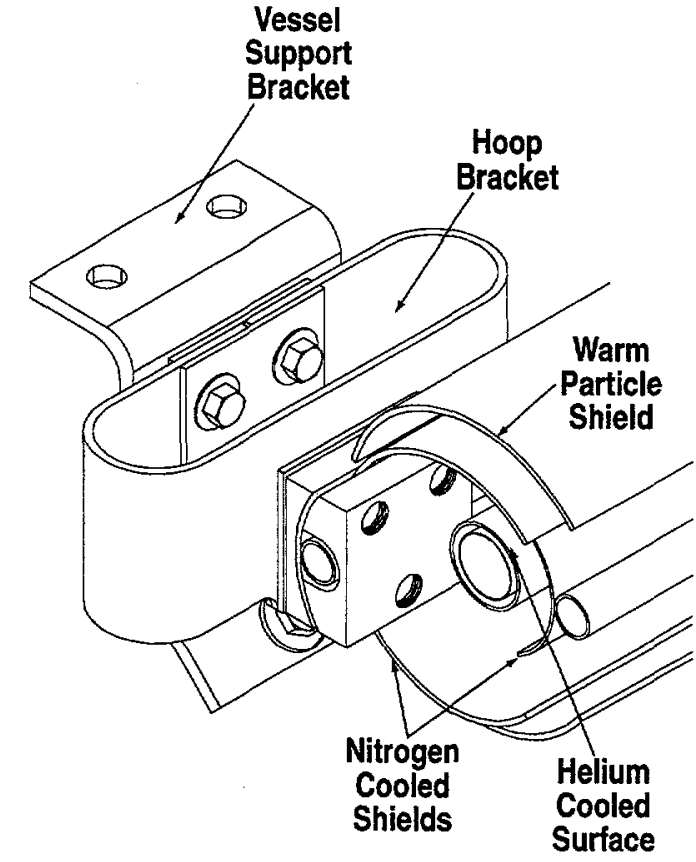

Fig. 2. Cryopump cross-section and support structure.

along the helium feedline for the inner pump. The outer cryopump helium feedline requires a support at the vertical port entrance and midway along its vertical run. Since the fatigue stress in the standoff is high even for Inconel 625 material, this support is machined and not welded.

The liquid helium enters the pump as saturated liquid and exists as two-phase helium. The mass flow rate for inboard pump is $5 \mathrm{~g} / \mathrm{s}$ at an inlet pressure of $115 \mathrm{kPa}$. The helium flow is shut down between plasma shots and the helium panel allowed to warm to $70 \mathrm{~K}$. This frequent regeneration of the helium tube limits frost buildup and the total quantity of gas that will be desorbed into the vessel. The liquid nitrogen components are designed to cool down within $30 \mathrm{~min}$ from $300 \mathrm{~K}$. The helium tubes chill down from 300 to $4 \mathrm{~K}$ in 3.0 min once the nitrogen shields are cooled.

The helium tube of the cryopump is subjected to a steadystate heat load of less than $10 \mathrm{~W}$ due to conduction and radiation heat transfer. The helium tubes are subjected to Joule heating of less than $300 \mathrm{~J}$ due to induced current and a particle load of less than $12 \mathrm{~W}$ during plasma operation. Thermal analyses and tests show that the helium tube can absorb a transient heat load of up to $100 \mathrm{~W}$ for $10 \mathrm{~s}$ and still pump deuterium at $6.3 \mathrm{~K}$.

\section{STRUCTURAL ANALYSIS}

Structural analyses were performed to verify that the combined stresses due to disruption loads, vessel motion, and restrained thermal contraction satisfy the criteria specified by Section III of the ASME code. The dynamic stress analysis of the inboard cryopump and feedlines was performed using beam and spring-mass structural models input to the COSMOS finite element code. The structural models were 


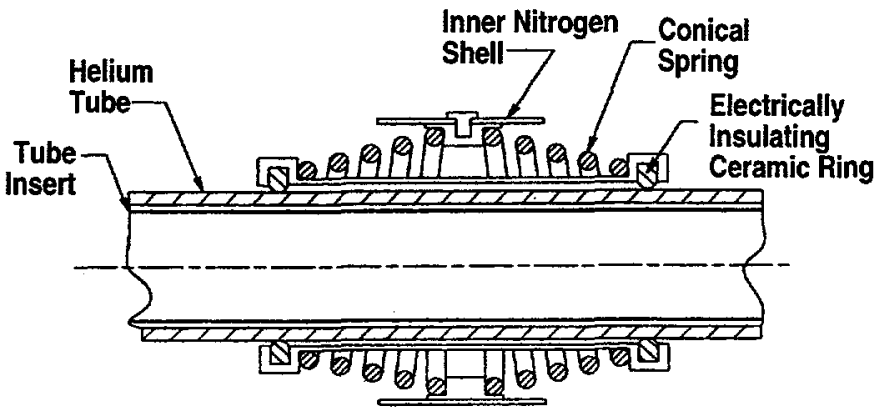

Fig. 3. Low heat leak liquid helium support.

also used to calculate the stresses and deflections due to dead weight and thermal contraction. The spring rates of the hoop spring supports to the vacuum vessel and the helium feed line standoffs were optimized using separate finite element models.

The disruption loads acting on the cryopump were calculated using magnetic measurements taken during plasma disruptions near the pump locations in DIII-D. The largest loads occur for those disruptions that terminate in rapid vertical displacement of the plasma. The dynamic loads used for the design and analysis of the pump were obtained by scaling the measure data to a 3.0 MA plasma at full toroidal field. The radial and vertical load impulses applied to the helium line and nitrogen shield are shown in Fig. 5. The disruption loads do not act upon the feedlines to the cryopump.

In addition to the disruption loads applied to the pump, the vacuum vessel oscillates vertically at $21 \mathrm{~Hz}$ following a vertical disruption of the plasma. The amplitude of the vertical motion input to the dynamic analysis is $2.5 \mathrm{~mm}$. The support system for the pump and the feedlines were designed to avoid the $21 \mathrm{~Hz}$ vessel motion that would cause amplification of the cryopump displacements. In order to increase the first two frequencies of the feedlines to the inner cryopump, a standoff between the nitrogen shield and the vessel port is required. The location of this standoff is $117 \mathrm{~cm}$ above the centerline of the pump. Standoffs between the helium feedline and nitrogen shield are also required at locations discussed above. The utilization of the these standoffs increases the fundamental frequency of the inner cryopump system to $39 \mathrm{~Hz}$. Due to the fairly tight clearance between the port opening of the vessel ceiling and the feedline, there is concern about contact between them. The total radial displacement at the elbow of the feedlines due to cooldown, disruption, and vessel motion is $3.6 \mathrm{~mm}$. This is less than the radial clearance of $4.7 \mathrm{~mm}$ designed for the port.

The maximum stresses in various components of the cryopump for disruption loads only and for disruption plus cooldown loads are summarized in Table I. The allowable stresses for Inconel 625 for disruption loads at room temperature are $414 \mathrm{Mpa}$ and $828 \mathrm{Mpa}$ for disruption plus cooldown loads. All components satisfy the ASME code criteria, except for the helium feedline standoff. The

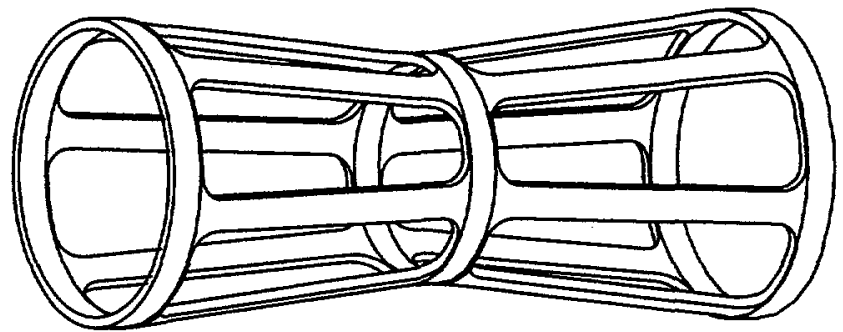

Fig. 4. Helium feed line support.

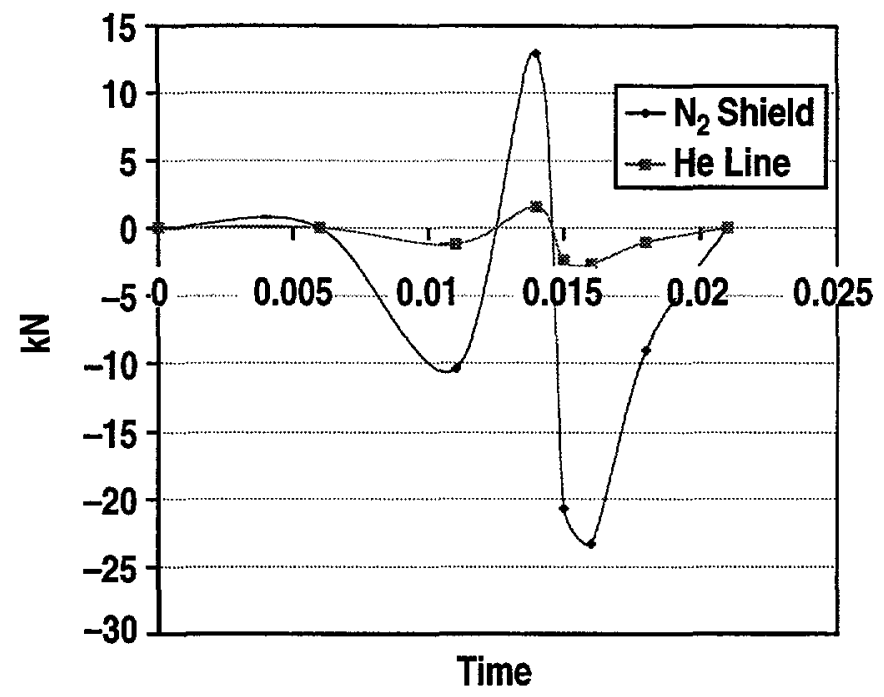

Fig. 5. Vertical disruption loads on inner cryopump.

maximum stress of $439 \mathrm{Mpa}$ is acceptable for the standoff since it is not a pressure boundary and the fatigue stresses in the standoff are less than the endurance limit for unwelded Inconel 625.

Results from the dynamic analyses showed that some impact forces will be developed in the helium spring support during a disruption event. Although the inboard helium line weighs only $12 \mathrm{lbs}$, there was concern that the impact forces on ceramic rings of the helium line supports (Fig. 3) could cause a cracking failure. To investigate the effects of the helium support springs bottoming out during maximum disruption conditions, a two DOF spring-mass-gap model was utilized. The calculated impulse load on the helium supports was used as input to impact tests performed on the support at an independent testing facility. Visual inspection of the ceramic rings after multiple impulse loadings showed that no cracking had occurred.

\section{SUMMARY}

The cryopumps for the DIII-D divertor required a mechanical design capable of reacting the routine toroidal currents and the disruption loads. The structural design of the cryopumps required the development of high strength support brackets and low heat leak standoffs for the helium feedlines. 
Table 1

Stress summary of inner cryopump components

\begin{tabular}{lcc}
\hline \multicolumn{1}{c}{ Component } & $\begin{array}{c}\text { Disruption + W } \\
\text { Motion (MPa) }\end{array}$ & $\begin{array}{c}\text { Disruption/W } \\
\text { Motion + T.E. }+ \\
\text { D.W. (MPa) }\end{array}$ \\
\hline Nitrogen shield & 49 & 163 \\
Helium line & 184 & 198 \\
Nitrogen adapter & 8 & 117 \\
Nitrogen can & 28 & 108 \\
$\begin{array}{l}\text { Nitrogen feed at first } \\
\text { weld to can }\end{array}$ & 155 & 217 \\
$\begin{array}{l}\text { Helium feedline } \\
\text { Nitrogen feed at first }\end{array}$ & 91 & 118 \\
weld to N $_{2}$ shield & 25 & 61 \\
$\begin{array}{l}\text { Nitrogen tee feed at } \\
\text { adapter }\end{array}$ & 76 & 96 \\
Helium feed support & 242 & 250 \\
$\begin{array}{l}\text { Hoop bracket } \\
\text { (Inconel } 718 \text { ) }\end{array}$ & 594 & 1056 \\
\hline
\end{tabular}

Thermal analysis and tests show that the helium tubes can absorb a transient heat load of up to $100 \mathrm{~W}$ for $10 \mathrm{~s}$ and still pump deuterium at $6.3 \mathrm{~K}$. Extensive static and dynamic analyses were performed to verify that the combined stresses due disruption loads, vessel motion, and restrained thermal contraction satisfy the criteria specified by Section III of the ASME code.

\section{REFERENCES}

[1] J.P. Smith, et al., "A Cryocondensation Pump for the DIII-D Advanced Divertor Program," Fusion Technol. 21, 1658 (1992).

[2] E.E. Reis, et al., "Design and Analysis of the Cryopump for the DIII-D Advanced Divertor," Proc. of the 17th Symp. on Fusion Technology, Rome, Italy, 1992, Vol. 1, 348 (1993).

[3] A.S. Bozek, et al., "Engineering Design of Cryocondensation Pumps for the DIII-D Radiative Divertor Program," Proc. of the 16th Symp. on Fusion Engineering, Champaign, Illinois, 1995, Vol. 2, 898 (1996).

[4] M.A. Hollerbach and J.P. Smith, "Fabrication and Installation of the DIII-D Radiative Divertor Structures," Proc. of the 17th Symp. on Fusion Engineering, San Diego, California, 1997, Vol. 1, 377, (1998).

[5] A.S. Bozek, et al., "Pumping Characteristics of the DIII-D Cryopump," these Proceedings. 